\title{
Assessment of functional capacity of offspring of hypertensive versus normotensive parents by 6 minute walk test.
}

\author{
Noopur Srivastava ${ }^{1}$, Sourya Acharya ${ }^{2}$, Samarth Shukla ${ }^{3}$ \\ ${ }^{I}$ Student \\ ${ }^{2}$ Professor, Dept. Of Medicine \\ ${ }^{3}$ Professor, Dept. Of Pathology JN Medical College DMIMSU Sawangi (M) Wardha
}

\begin{abstract}
Introduction: Hypertension is one of the commonest worldwide disease afflicting humans. It is an important public health challenge. A new analysis shows that in 2000 nearly one billion of the world's population was hypertensive and suggests that the global burden of hypertension may reach 1.56 billion people worldwide by 2025.The situation of hypertensive disorders in India is more alarming.

AIM- To assess the functional capacity of offspring of hypertensive parents with control group (offspring of normotensive parents) by 6 minute walk test.

Methods: A cross-sectional study is carried out in DMIMSU with 100 subjects (of hypertensive and normotensive parents) taken into consideration using 6 minute walk test. The comparison is done on the basis of physiological parameters mainly as $6 \mathrm{MWD}, \mathrm{VO}_{2}$ Max, Walk Work.

Results: The $6 \mathrm{MWD}$ covered and the $\mathrm{VO}_{2}$ max consumed by the offspring of hypertensive parents is less than the normotensive parents.

Conclusion: The functional capacity of study group comes out to be less than control group. Therefore, study group should adopt primordial preventive measures to avoid the risk of developing hypertension in future.
\end{abstract}

Key Words: Hypertension, Functional capacity, 6 Minute Walk Test, $\mathrm{VO}_{2}$ Max.

\section{Introduction}

Hypertension is one of the commonest worldwide disease afflicting humans. Because of the associated morbidity and mortality and the cost to society, hypertension is an important public health challenge. Hypertension is a progressive cardiovascular syndrome with many causes that result in both functional and structural changes to the heart and vascular systems.

A new analysis shows that in 2000 nearly one billion of the world's population was hypertensive and suggests that the global burden of hypertension may reach 1.56 billion people worldwide by 2025 .The situation of hypertensive disorders in India is more alarming. Hypertension is directly responsible for $57 \%$ of all stroke deaths and $24 \%$ of all coronary heart disease death in India. ${ }^{(1)}$

Emerging as a major health problem in most of the developing countries, hypertension is a multifactorial disease influenced by environmental and genetic factors. Although the identification of environment risk factors has led to the treatment of disease, our knowledge of its heritability is very limited to the predictive importance of a positive family history or to the observation of familial segregation.

This study aims to investigate the effects of parental hypertension in the children of hypertensive parents through a physical test i.e. 6 minute walk test.

The six minute walk test is an objective measure of functional exercise capacity in individuals with moderately severe impairment of cardiovascular and respiratory conditions. ${ }^{(2)}$ It is safer, easier to administer, better tolerated and

better reflects activities of daily living. This test records the distance (6MWD) an individual is able to walk along a flat $30 \mathrm{~m}$ walkway over 6 minute period, with breaks as required. ${ }^{(2)}$

Using 6 minute walk distance (6MWD) and few other physiological parameters, this test targets to find Out effects of parental hypertension by comparing functional exercise capacity of offspring of hypertensive and Normotensive parents.

\section{Objectives}

1) To compare the physical fitness of offspring of hypertensive (study group) and nonhypertensive parents (control group).

2) To compare the offspring of hypertensive and nonhypertensive on the basis of physiological parameters. 


\section{Methodology}

SITE OF STUDY - Jawaharlal Nehru Medical College(JNMC) attached to Acharya Vinobha Bhave Rural Hospital(A.V.B.R.H), a 909 bedded rural tertiary hospital of Datta Meghe Institute Of Medical Sciences(DMIMS)(Grade "A" accredited by NAAC), Sawangi(Meghe), Wardha.

STUDY TYPE - The study is cross-sectional type of study.

DURATION OF STUDY - The duration of study was 2 months.

SAMPLE SIZE - A sample of 100 subjects (male and female) of hypertensive and normotensive parents has been studied.

\section{Inclusion Criteria -}

1) Normal subjects (student of JNMC) of hypertensive and nonhypertensive parents.

2) Subjects between age group of 18-25 yrs have been taken into account.

\section{Exclusion Criteria-}

1) Subjects with pre-existing disorders such as cardiovascular disorders, respiratory diseases and asthma.

2) Subjects who did not give consent.

\section{Six Minute Walk Test}

A long, flat, straight, enclosed $30 \mathrm{~m}$ college corridor marked by colour tape at each end has been used. Subjects were instructed to walk from end to end at their self-selected pace, while attempting to cover as much distance as possible in 6 minute.

Use- To evaluate the physical functional capacity of an individual so as to assess

His/ her fitness. ${ }^{(2)}$

\section{Other Uses-}

diseases ${ }^{(2)}$

- It is also necessary to develop reference equations to interpret the results for comparison between the healthy and unhealthy population. ${ }^{(2)}$

Requirements- 1) a countdown time

2) Cones to mark turnaround points

3) A chair if subject needs to rest during testing

Subject Preparation-

4) Sphygmomanometer

1) Comfortable clothing should be worn.

2) A light meal is acceptable before early morning or early afternoon Tests.

3) Subject should not have exercised vigorously within $2 \mathrm{hrs}$ of

Beginning the test.

4) Subject should not have taken any medications before

Commencing the test.

Physiological parameters -

The following physiological parameters are studied before test and after the test on the subjects and the results are obtained on the basis of their comparison between the two groups (study group and the control group).

\begin{tabular}{|l|l|}
\hline \multicolumn{1}{|c|}{ PRE-TEST } & \multicolumn{1}{c|}{ POST-TEST } \\
\hline 1)Mental status & 1)Distance covered(6MWD)- recorded \\
\hline 2)Heart rate & 2)Heart rate \\
\hline 3)Blood pressure & 3)Blood pressure \\
\hline 4)Body mass index(BMI) & 4)Dyspnoea and Fatigue - Borg scale ${ }^{(3)}$ \\
\hline & 5)Walk work * \\
\hline & 6) $\mathrm{VO}_{2}$ max ** \\
\hline & \\
\hline
\end{tabular}

*Calculation of walk work ${ }^{(4)}=$ body weight $(\mathrm{kg}) \times$ distance covered $(\mathrm{m})$

**Calculation of $\mathrm{VO}_{2}$ max ${ }^{(5)}=$

- $\quad$ Energy expenditure $(\mathrm{kcal})=$ walk work $(\mathrm{kgm}) \div 426.8$

Or 


$$
=\text { walk work }(\mathrm{kgm}) \times\left(2.342 \times 10^{-3}\right)
$$

- $\mathrm{Kcal} / \mathrm{min}=$ Energy expenditure $(\mathrm{kcal}) \div 6$

Finally, cal/min was converted to oxygen consumption by following equation:-

- $\mathrm{O}_{2}(1 / \mathrm{min})=(\mathrm{kcal} / \mathrm{min}) \times 5 \cdot \cdot 1 \mathrm{lit}=5 \mathrm{kcal}$

- $\quad \mathrm{VO}_{2} \max (\mathrm{ml} / \mathrm{kg} / \mathrm{min})=\left(\mathrm{O}_{2}(\mathrm{lit} / \mathrm{min}) \times 1000\right) \div$ body weight $(\mathrm{kg})$

The statistical data of both the groups was compared separately. On the other hand the physiological parameters of female offspring of both groups i.e. hypertensive parents and normotensive parents were also considered separately as according to literature females cover less distance in 6 minute walk test. ${ }^{(2)}$

Collection, presentation and interpretation of data-

The data obtained after the completion of test is collected and presented in tabular as well as graphical forms. It is interpreted statistically and analysed using following methods:-

1) Chi-square test

2) Z test

All data analysis is performed using statistical software SPSS.

\section{Results}

1) Mental status- Normal

2) Heart rate pre-test and post test- Tachycardia was present post test in all the Subjects but overall evaluation of heart rate came out to be within the normal range. Recovery time-30 sec to 1 minute.

3) Blood pressure pre-test and post test-within the normal range.

SBP- $<130 \mathrm{mmHg}$

DBP- $<90 \mathrm{mmHg}$

4) Dyspnoea (as evaluated through Borg scale) - Range lied between 6-11 Post test.

\section{Analysis Of The Data Obtained-}

Table 1: Comparison of 6 min walk distance (m) in offspring of Normotensive and Hypertensive Parents.

1(a) Descriptive Statistics of 6 min walk distance compared in offspring of normotensive and hypertensive parents.

\begin{tabular}{|l|l|l|l|l|l|}
\hline & & N & Mean & Std. Deviation & $\begin{array}{l}\text { Std. Error } \\
\text { Mean }\end{array}$ \\
\hline \multirow{2}{*}{ Male Offspring } & Normotensive Parents & 25 & 766.62 & 84.47 & 16.89 \\
\cline { 2 - 6 } & Hypertensive Parents & 25 & 670.90 & 94.37 & 18.87 \\
\hline \multirow{2}{*}{ Female Offspring } & Normotensive Parents & 25 & 600.56 & 42.48 & 8.49 \\
\cline { 2 - 6 } & Hypertensive Parents & 25 & 548.09 & 60.19 & 12.03 \\
\hline \multirow{2}{*}{ Total Subjects } & Normotensive Parents & 50 & 718.76 & 100.97 & 14.28 \\
\cline { 2 - 6 } & Hypertensive Parents & 50 & 574.33 & 57.97 & 8.19 \\
\hline
\end{tabular}

1(b) Analytical Statistics of 6 min walk distance compared in offspring's of normotensive and hypertensive parents by application of Student's unpaired t test.

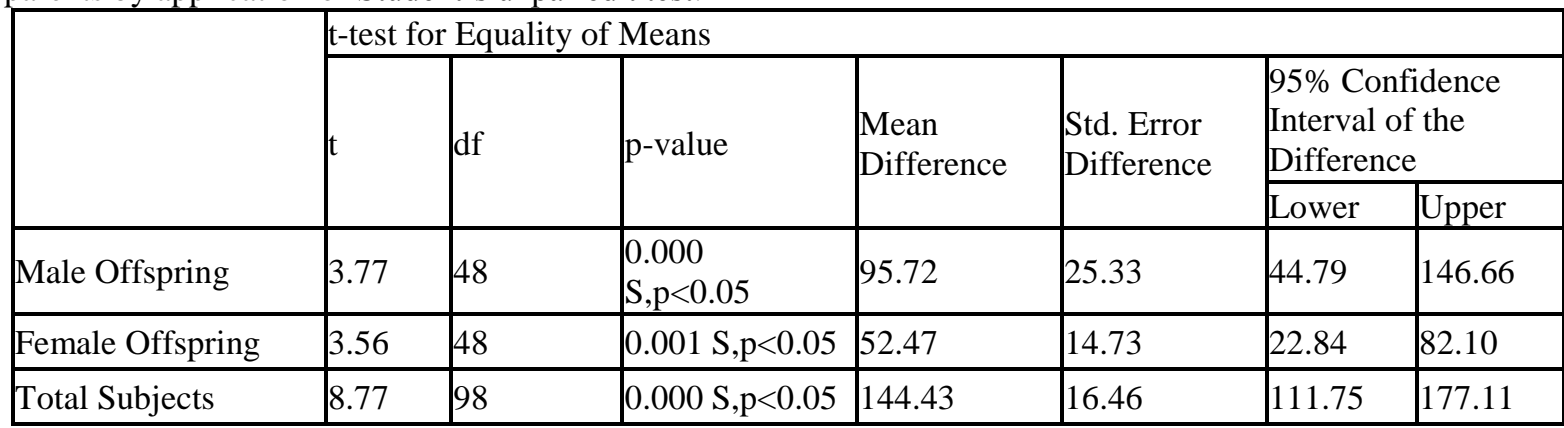

Mean 6MWD in male offspring of normotensive parents was $766.62 \pm 84.47$ and in hypertensive parents it was $670.90 \pm 94.37$. By using student unpaired t test statistically significant difference was found in 6MWD in both the groups $(\mathrm{t}=3.77, \mathrm{p}=0.000)$.

Mean 6MWD in female offspring of normotensive parents was $600.56 \pm 42.48$ whereas in hypertensive parents it was548.09 \pm 60.19 . Statistically significant difference was found in 6MWD in both the groups $(t=3.56$, $\mathrm{p}=0.001)$. 
Mean 6MWD in total subjects of normotensive parents was $718.76 \pm 100.97$ whereas in hypertensive parents it was $574.33 \pm 57.97$ Statistically significant difference was found in $6 \mathrm{MWD}$ in both the groups $(\mathrm{t}=8.77, \mathrm{p}=0.000)$.

Graph 1: Comparison of 6 min walk distance (m) in offspring's of Normotensive and Hypertensive Parents.

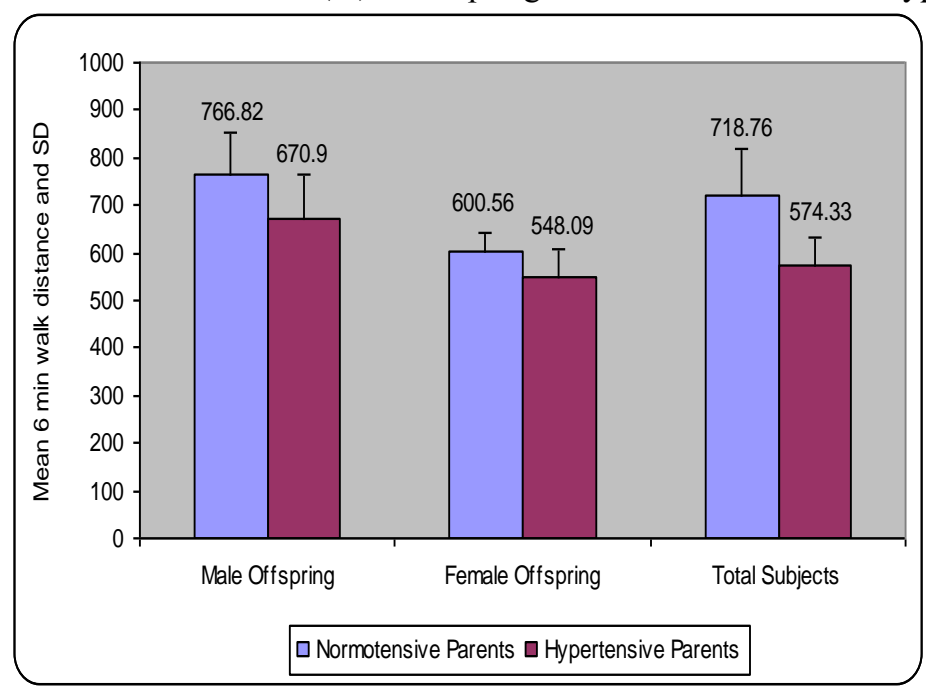

Table 2: Comparison of $\mathrm{VO}_{2} \mathrm{Max}(\mathrm{ml} / \mathrm{kg} / \mathrm{min})$ in offspring of Normotensive and Hypertensive Parents. 2(a) Descriptive Statistics of $\mathrm{VO}_{2}$ Max compared in offspring's of normotensive and hypertensive parents.

\begin{tabular}{|l|l|l|l|l|l|}
\hline & & $\mathrm{N}$ & Mean & Std. Deviation & Std. Error Mean \\
\hline \multirow{3}{*}{ Male Offspring } & Normotensive Parents & 25 & 1496.89 & 165.01 & 33.00 \\
\cline { 2 - 7 } & Hypertensive Parents & 25 & 1311.76 & 181.30 & 36.26 \\
\hline \multirow{2}{*}{ Female Offspring } & Normotensive Parents & 25 & 1173.28 & 82.90 & 16.58 \\
\cline { 2 - 7 } & Hypertensive Parents & 25 & 1074.91 & 117.59 & 23.51 \\
\hline \multirow{2}{*}{ Total Subjects } & Normotensive Parents & 50 & 1404.32 & 195.40 & 27.63 \\
\cline { 2 - 6 } & Hypertensive Parents & 50 & 1124.09 & 112.28 & 15.87 \\
\hline
\end{tabular}

2(b) Analytical Statistics of $\mathrm{VO}_{2}$ Max compared in offspring's of normotensive and hypertensive parents by Student's unpaired t test.

\begin{tabular}{|c|c|c|c|c|c|c|c|}
\hline & \multicolumn{7}{|c|}{ t-test for Equality of Means } \\
\hline & $\mathrm{t}$ & \multirow[t]{2}{*}{$\mathrm{df}$} & \multirow[t]{2}{*}{ p-value } & \multirow[t]{2}{*}{ Mean Difference } & \multirow{2}{*}{$\begin{array}{l}\text { Std. Error } \\
\text { Difference }\end{array}$} & \multicolumn{2}{|c|}{$\begin{array}{l}95 \% \text { Confidence Interval of the } \\
\text { Difference }\end{array}$} \\
\hline & & & & & & Lower & Upper \\
\hline Male Offspring & 3.77 & 48 & $\begin{array}{l}0.000 \\
\mathrm{~S}, \mathrm{p}<0.05\end{array}$ & 185.13 & 49.03 & 86.55 & 283.72 \\
\hline Female Offspring & 3.41 & 48 & $\begin{array}{l}0.001 \\
\mathrm{~S}, \mathrm{p}<0.05\end{array}$ & 98.36 & 28.77 & 40.51 & 156.22 \\
\hline Total Subjects & 8.79 & 98 & $\begin{array}{l}0.000 \\
\mathrm{~S}, \mathrm{p}<0.05\end{array}$ & 280.23 & 31.87 & 216.98 & 343.48 \\
\hline
\end{tabular}

Mean $\mathrm{VO}_{2}$ Max in male offspring of normotensive parents was $1496.89 \pm 165.01$ and in hypertensive parents it was $1311.76 \pm 181.30$. By using student unpaired t test statistically significant difference was found in $\mathrm{VO}_{2}$ Max in both the groups $(\mathrm{t}=3.77, \mathrm{p}=0.000)$.

Mean $\mathrm{VO}_{2}$ Max in female offspring of normotensive parents was $1173.28 \pm 82.90$ whereas in hypertensive parents it was $1074.91 \pm 117.59$. Statistically significant difference was found in $\mathrm{VO}_{2} \mathrm{Max}_{\text {in }}$ both the groups $(\mathrm{t}=3.41, \mathrm{p}=0.001)$.

Mean $\mathrm{VO}_{2}$ Max in total subjects of normotensive parents was $1404.32 \pm 195.50$ whereas in hypertensive parents it was $1124.09 \pm 112.28$. Statistically significant difference was found in $\mathrm{VO}_{2} \mathrm{Max}$ in both the groups $(\mathrm{t}=8.79, \mathrm{p}=0.000)$. 
Graph 2: Comparison of $\mathrm{VO}_{2} \mathrm{Max}(\mathrm{ml} / \mathrm{kg} / \mathrm{min})$ in Offspring of Normotensive And Hypertensive Parents.

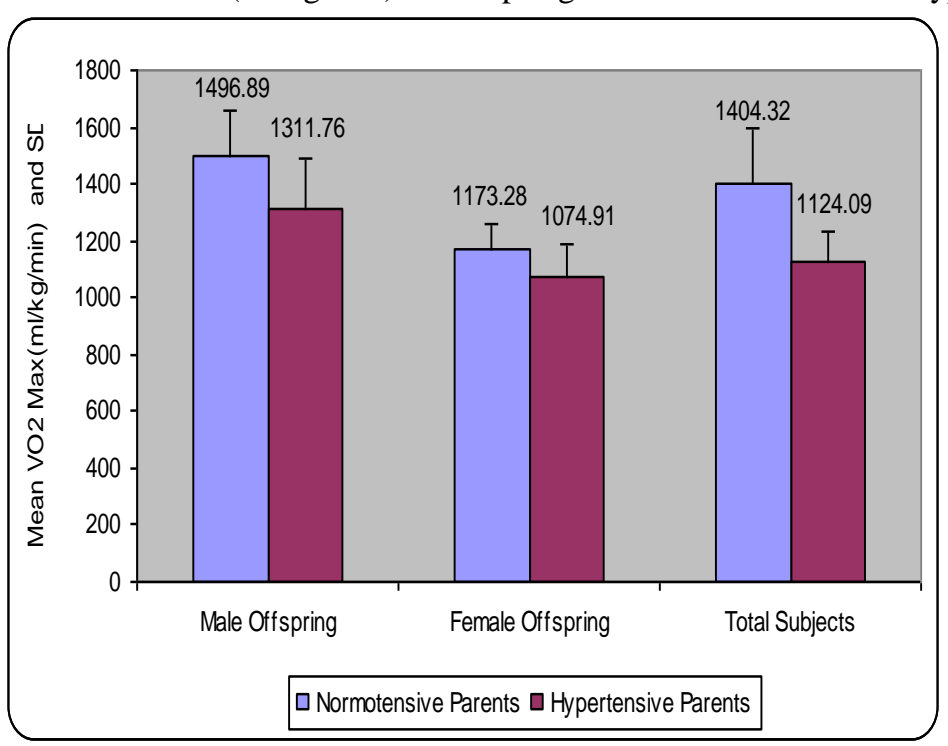

Table 3: Comparison of Walk Work (Kgm) in Offspring of Normotensive and Hypertensive Parents. 3(a) Descriptive Statistics of walk work compared in offspring of normotensive and hypertensive parents.

\begin{tabular}{|l|l|l|l|l|l|}
\hline & & N & Mean & Std. Deviation & Std. Error Mean \\
\hline \multirow{2}{*}{ Male Offspring } & Normotensive Parents & 25 & 52455.16 & 11216.681 & 2243.33 \\
\cline { 2 - 6 } & Hypertensive Parents & 25 & 48163.90 & 8302.25 & 1660.45 \\
\hline \multirow{2}{*}{ Female Offspring } & Normotensive Parents & 25 & 30574.50 & 4399.57 & 879.91 \\
\cline { 2 - 6 } & Hypertensive Parents & 25 & 30130.29 & 6428.30 & 1285.66 \\
\hline \multirow{2}{*}{ Total Subjects } & Normotensive Parents & 50 & 50309.53 & 10004.06 & 1414.78 \\
\cline { 2 - 6 } & Hypertensive Parents & 50 & 30352.40 & 5456.26 & 771.63 \\
\hline
\end{tabular}

3(b) Analytical Statistics of walk work compared in offspring of normotensive and hypertensive parents by Student's unpaired t test.

\begin{tabular}{|l|l|l|l|l|l|l|l|}
\hline & $\mathrm{t}$ & $\mathrm{t}$-test for Equality of Means & Mean Difference & $\begin{array}{l}\text { Std. Error } \\
\text { Difference }\end{array}$ & \multicolumn{3}{l|}{$\begin{array}{l}\text { 95\% Confidence Interval of the } \\
\text { ifference }\end{array}$} \\
\cline { 2 - 8 } & $\mathrm{t}$ & $\mathrm{df}$ & $\mathrm{p}$-value & Lower & Upper \\
\hline Male Offspring & 1.53 & 48 & $\begin{array}{l}0.131 \\
\mathrm{NS}, \mathrm{p}>0.05\end{array}$ & 4291.26 & 2790.99 & -1320.41 & 9902.93 \\
\hline Female Offspring & 0.28 & 48 & $0.777 \mathrm{NS}, \mathrm{p}>0.05$ & 444.21 & 1557.93 & -2688.23 & 3576.65 \\
\hline Total Subjects & 12.38 & 98 & $\begin{array}{l}0.000 \\
\mathrm{~S}, \mathrm{p}<0.05\end{array}$ & 19957.120 & 1611.53 & 16759.09 & 23155.16 \\
\hline
\end{tabular}

Mean walk work in male offspring of normotensive parents was $52455.16 \pm 11216.68$ and in hypertensive parents it was $48163.90 \pm 8302.25$. By using student unpaired t test statistically significant difference was found in walk work in both the groups $(\mathrm{t}=1.53, \mathrm{p}=0.131)$.

Mean walk work in female offspring of normotensive parents was $30574.50 \pm 4399.57$ whereas in hypertensive parents it was $30130.29 \pm 6428.30$. Statistically significant difference was found in walk work in both the groups $(\mathrm{t}=0.28, \mathrm{p}=0.777)$.

Mean walk work in total subjects of normotensive parents was $50309.53 \pm 10004.06$ whereas in hypertensive parents it was $30352.40 \pm 5456.26$. Statistically significant difference was found in walk work in both the groups $(\mathrm{t}=12.38, \mathrm{p}=0.000)$. 
Graph 3: Comparison of Walk Work (Kgm) in offspring of Normotensive and Hypertensive Parents.

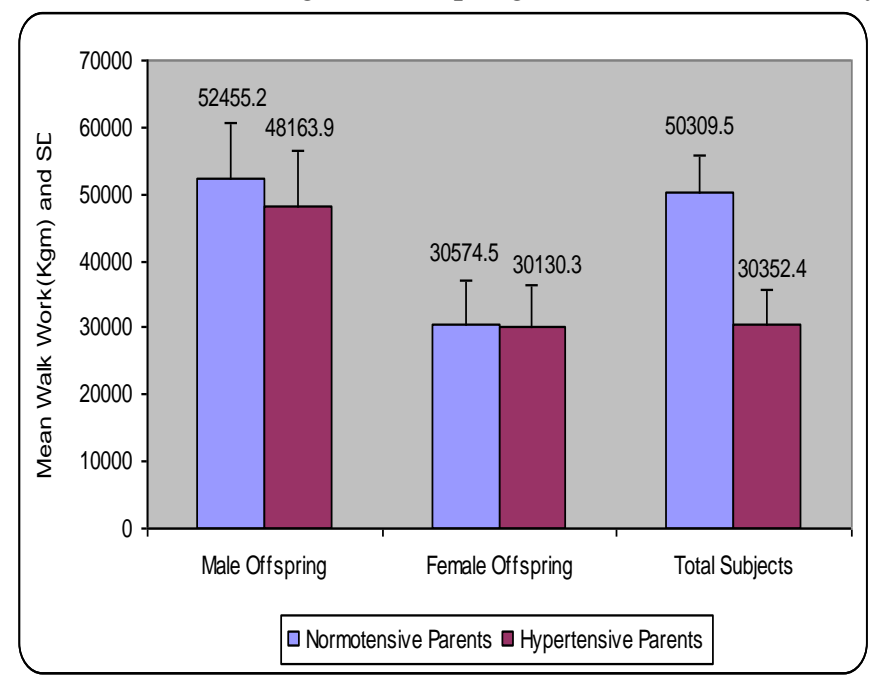

Table 4: Comparison of BMI $\left(\mathrm{kg} / \mathrm{m}^{2}\right)$ in offspring of Normotensive and Hypertensive Parents. 4(a) Descriptive Statistics of BMI compared in offspring of normotensive and hypertensive parents.

\begin{tabular}{|l|l|l|l|l|l|}
\hline & & $\mathrm{N}$ & Mean & Std. Deviation & Std. Error Mean \\
\hline \multirow{3}{*}{ Male Offspring } & Normotensive Parents & 25 & 22.14 & 4.14 & 0.82 \\
\cline { 2 - 7 } & Hypertensive Parents & 25 & 23.84 & 4.49 & 0.89 \\
\hline \multirow{2}{*}{ Female Offspring } & Normotensive Parents & 25 & 20.02 & 2.10 & 0.42 \\
\cline { 2 - 6 } & Hypertensive Parents & 25 & 22.03 & 3.41 & 0.68 \\
\hline \multirow{2}{*}{ Total Subjects } & Normotensive Parents & 50 & 22.99 & 4.36 & 0.61 \\
\cline { 2 - 6 } & Hypertensive Parents & 50 & 21.02 & 2.99 & 0.42 \\
\hline
\end{tabular}

4(b) Analytical Statistics of BMI compared in offspring of normotensive and hypertensive parents by Student's unpaired $t$ test.

\begin{tabular}{|c|c|c|c|c|c|c|c|}
\hline & \multicolumn{7}{|c|}{ t-test for Equality of Means } \\
\hline & \multirow[t]{2}{*}{$\mathrm{t}$} & \multirow[t]{2}{*}{ df } & \multirow[t]{2}{*}{ p-value } & \multirow[t]{2}{*}{ Mean Difference } & \multirow[t]{2}{*}{$\begin{array}{l}\text { Std. Error } \\
\text { Difference }\end{array}$} & \multicolumn{2}{|c|}{\begin{tabular}{|l|}
$95 \%$ Confidence \\
Interval of the \\
Difference \\
\end{tabular}} \\
\hline & & & & & & Lower & Upper \\
\hline Male Offspring & 1.39 & 48 & $\begin{array}{l}0.169 \\
N S, p>0.05\end{array}$ & -1.70 & 1.22 & -4.16 & 0.75 \\
\hline Female Offspring & 2.51 & 48 & $\begin{array}{l}0.015 \\
\mathrm{~S}, \mathrm{p}<0.05\end{array}$ & -2.01 & 0.80 & -3.63 & -0.40 \\
\hline Total Subjects & 2.62 & 98 & $0.010 \mathrm{~S}, \mathrm{p}<0.05$ & 1.96 & 0.74 & 0.48 & 3.44 \\
\hline
\end{tabular}

Mean BMI in male offspring of normotensive parents was $22.14 \pm 4.14$ and in hypertensive parents it was 23.84 \pm 4.49 . By using student unpaired $t$ test statistically significant difference was found in BMI in both the groups $(\mathrm{t}=1.39, \mathrm{p}=0.169)$.

Mean BMI in female offspring of normotensive parents was 20.02 \pm 2.10 whereas in hypertensive parents it was 22.03 \pm 3.41 . Statistically significant difference was found in BMI in both the groups $(\mathrm{t}=2.51$, $\mathrm{p}=0.015)$.

Mean BMI in total subjects of normotensive parents was $22.99 \pm 4.36$ whereas in hypertensive parents it was 21.02 \pm 2.99 . Statistically significant difference was found in BMI in both the groups $(\mathrm{t}=2.62, \mathrm{p}=0.010)$. 
Graph 4: Comparison of BMI (kg/m2) in Offspring of Normotensive and Hypertensive Parents.

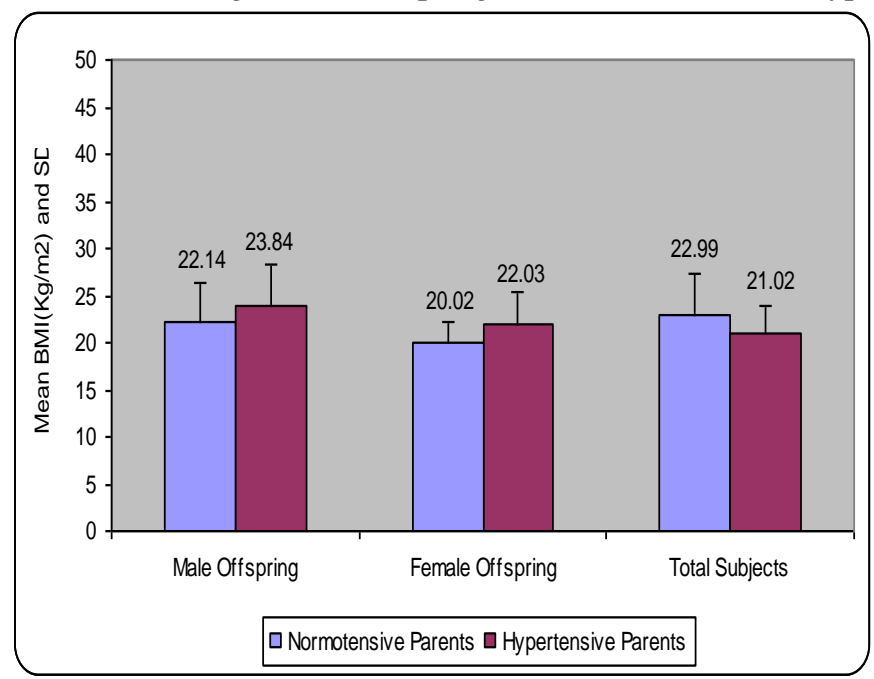

\section{Discussion}

This study titled "Assessment of functional capacity of offspring of hypertensive versus normotensive parents by 6 minute walk test." was carried out in JN Medical college attached to DMIMS university, Wardha. The 6 minute walk distance (6MWD), $\mathrm{VO} 2$ max in children of hypertensive parents was less than children of normotensive parents and the results were statistically significant. This significant difference was true for the male and the female offspring separately. Though the young adults of hypertensive parents were healthy still their capacity to walk more in a limited period of time which demanded fitness was less ,suggesting that the cardiovascular and respiratory fitness was more in children of normotensive parents. The mean BMI of the offspring of hypertensive parents was significantly high than that of the off spring of normotensive parents. Lot of studies have confirmed that the physical fitness and exercise capacity are adversely affected in nomotensive adults and adolescents with high BMI by 6 minute walk test. ${ }^{(6,7)}$ Another study proved that exercise capacity in 6 minute walk test improved after weight reduction suggesting that modifiable risk factors do help in risk reduction. ${ }^{(8)}$

In our study also the 6MWD covered by the study group was less than that of control group, walk work done by children of normotensive parents was better than the children of hypertensive parents, who also had higher BMI. The exertion perceived during the test caused dyspnoea was measured by Borg scale and the range lied between 6 and 11 which signify very light to fairly light level of exertion subjectively. Although 2-3 subjects perceived greater level of exertion beyond 13(hard to very hard) according to scale but it was insignificant. This was an expected phenomenon because the offspring of hypertensive parents were normal subjects.

Another study evaluated cardiovascular functional capacity as well as the heart rate (HR) and blood pressure responses to a 6 minute walk test (6MWT) between normotensive offsprings of normotensive parents (NTP) and hypertensive parents (HTP). 60 subjects within the age group of 18 to 25 years were studied. Basal Heart Rate (BHR), Systolic Blood Pressure (SBP) and Diastolic Blood Pressure (DBP) were noted before the 6MWT. After performing 6MWT, the peak HR, SBP, DBP and the recovery pattern of these parameters and distance covered were recorded. The study revealed that resting DBP was significantly higher in the offspring of hypertensive parents. There was decreased DBP response to exercise in the offspring of the hypertensive parents. Though the $6 \mathrm{MW}$ distance did not change between the two study groups. The study concluded that there was an early trend in higher blood pressure in the offspring of hypertensive parents. Suggesting that an early genetic influence on blood pressure does exist on the offspring of hypertensive parents. ${ }^{(9)}$

Though hereditary and genetic factors contribute for the development of hypertension, exercise capacity and physical fitness are largely modifiable at personal levels. Life style modifications in regards to dietary interventions (DASH diet), moderation in salt intake and regular aerobic exercises have been highly recommended in JNC 7 and has also been emphasized in the recent JNC 8 guidelines though major changes has taken place as far as blood pressure goals are concerned, suggesting that prevention is, will and always remain the gold standard in approach to any disease in medicine. It is again needless to emphasize that early detection of the high risk group and early intervention will make a paradigm shift in the future consequences for hypertension.

The results of this study points out that being already vulnerable on the basis of hereditary and genetic factors, the off spring of hypertensive parents are still unable to overcome the stigmata of adverse modifiable 
risk factors for future hypertension, coronary artery disease, metabolic syndrome, diabetes mellitus. This study also highlights the importance of the 6-minute walk test as a simple effective tool to evaluate physical fitness levels in the apparently healthy looking high risk group who are the vast target of the iceberg lying beneath the sea level. The most important finding in this was the increased BMI in the target group which was significantly more than the control group. The low level can be well attributed to raised BMI.

This study suggests that normotensive children of hypertensive parents should increase their level of physical fitness and exercise capacity. Weight reduction, dietary modification and regular exercise are mandatory for these subjects to prevent future catastrophes.

\section{Conclusion:}

This study recommends that offspring of hypertensive parents with increased BMI and decreased physical fitness levels should be considered as high risk group for development of future cardiovascular events. Health education, lifestyle modification, exercise promotion, and primary prophylaxis to avoid the risk of developing hypertension and other cardiovascular morbidities should be adhered and implemented in this group. This study concluded that functional capacity of normotensive offspring of hypertensive parents is less than the offspring's of normotensive parents suggesting remedial intervention to increase fitness levels and avoid future cardiovascular risks. 6- minute walk test is a simple, effective tool to detect the fitness levels in these high risk population.

\section{References}

[1]. Rodgers A, Lawes C, MacMohan. Reducing the global burden of blood pressure related cardiovascular diseases. J Hypertens 2000; 18(suppl 1): S3-S6.

[2]. ATS statement: guidelines for the six minute walk test. Am J Respair Crit Care Med 2002: 166(1):111-117.

[3]. Borg, G, "Perceived Exertion as an indicator of somatic stress", scadinavian journal of Rehabilitation Medicine 1970, 2(2), 92-98.

[4]. Carter R, David B, et al. 6-Minute walk work for assessment of functional in patient with COPD. Chest. 2003; 123:1408-1415.

[5]. Cahalin L, Pappagianopoulas P et al.Relationship of 6-min walk test to Maximal oxygen consumption in transplant candidates with end stage lung disease. Chest. 1995; 108:452-459.

[6]. Hulens M, Vansant G, Claessens AL, Lysens R, Muls E. Predictors of 6-minute walk test results in lean, obese and morbidly obese women. Scand J Med Sci Sports. 2003 Apr;13(2):98-105.

[7]. Hulens M, Vansant G, Lysens R, Claessens AL, Muls E. Exercise capacity in lean versus obese women. Scand J Med Sci Sports. 2001 Oct;11(5):305-9.

[8]. Ekman, M J et al; 6-minute walk test before and after a weight reduction program in obese subjects. (2013) In Obesity (Silver Spring, Md.) 21(3). p.E236-E243.

[9]. Tarpan S, Shailaja M N, Harsha NH, Mirajkar AM. Assessment of Cardiovascular Functional Capacity and Response to Exercise in Normotensive Offsprings of Hypertensive Parents. Indian Journal of Physiotherapy and Occupational Therapy.2013: 7( 2);191-5. 